\title{
Artigo

\section{Discursos em disputa sobre a Bibliotheca Infantil em O Paiz (1894-1899)}

Márcia Cabral da Silva

Mariane Sousa Pinto

Universidade do Estado do Rio de Janeiro

\section{Resumo}

Neste estudo, analisam-se os discursos veiculados no periódico $\bigcirc$ Paiz sobre a conformação da Bibliotheca Infantil da Livraria do Povo. A imprensa como fonte privilegiada no âmbito da pesquisa histórica permite a reflexão sobre o contexto social, políitico e cultural, além de estabelecer estratégias de formação da opinião pública. Através de notas críticas, artigos e anúncios sobre a Biblioteca Infantil veiculados no jornal, objetivou-se perceber as tensões e as disputas discursivas em torno da conformação da referida biblioteca. Sobre as possibilidades de análise dos discursos em $O$ Paiz, adotou-se, sobretudo, a perspectiva bakhtiniana. Tendo em vista as etapas de pesquisa já concluídas, observou-se a importância da livraria no que tange ao acesso à leitura no período analisado em razão da produção de livros baratos para o povo. Constatou-se, ainda, a acirrada disputa discursiva entre aqueles que pretendiam o domínio do campo editorial relativo aos livros destinados às crianças à época.

Palavras-chave: Bibliotheca infantil. O Paiz. Discursos.

\section{Discourses in dispute about the Bibliotheca Infantil (Children's Library) in O Paiz (1894-1899)}

\begin{abstract}
In this study, we analyze the speeches published in the periodical $\bigcirc$ Paiz about the conformation of the Bibliotheca Infantil (Children's Library) related to Livraria do Povo (Bookstore of the People). The press as a privileged source within the scope of historical research allows the reflection on the social, political and cultural context, as well as establishing strategies for forming public opinion. Through critical notes, articles and announcements about the Bibliotheca Infantil (Children's Library) published in the newspaper, the objective was to understand the tensions and discursive disputes surrounding the conformation of the library. Concerning the possibilities of the discourses' analysis in $O$ Paiz, we have adopted, especially, the Bakhtinian perspective. With a view of the research steps already completed we have observed the importance of the bookstore in regard to access to reading in the period analyzed because of the production of cheap books for the people. We have also noticed the fierce discursive dispute among those who intended to editorial domain related to the books aimed at the children at the time. Keywords: Bibliotheca Infantil (Children's Library). O Paiz. Discourses.
\end{abstract}




\section{Discursos en disputa sobre la Bibliotheca Infantil (Biblioteca Infantil) en O Paiz (1894-1899)}

\section{Resumen}

En este estudio, se analizan los discursos publicados en el periódico $\bigcirc$ Paiz sobre la conformación de la Bibliotheca Infantil (Biblioteca Infantil) de la Livraria do Povo (Librería del Pueblo). La prensa como fuente privilegiada en el ámbito de la investigación histórica permite la reflexión sobre el contexto social, político y cultural, además de establecer estrategias de formación de la opinión pública. A través de notas críticas, artículos y anuncios sobre la Biblioteca Infantil vehiculados en el periódico, se objetivó percibir las tensiones y las disputas discursivas en torno a la conformación de dicha biblioteca. Sobre las posibilidades de análisis de los discursos en El Paiz, se adoptó, sobre todo, la perspectiva bakhtiniana. En vista de las etapas de investigación ya concluidas, se observó la importancia de la librería en lo que se refiere al acceso a la lectura en el período analizado en razón de la producción de libros baratos para el pueblo. Se constató, además, la fuerte disputa discursiva entre aquellos que pretendían el dominio del campo editorial relativo a los libros destinados a los niños en la época.

Palabras clave: Bibliotheca Infantil (Biblioteca Infantil). $\bigcirc$ Paiz. Los discursos.

\section{Introdução}

Na historiografia do livro infantil em âmbito brasileiro, destacam-se as décadas finais do século XIX como período fértil no que diz respeito à produção de livros nacionais para a formação das crianças. Antes dessa época, grande parte da produção era importada de Portugal. Além desse fator, havia também a dificuldade em relação a uma linguagem pouco apropriada para esse público leitor, repleta de preciosismos, expressões estrangeiras, fato que devia dificultar a recepção das obras, conforme as impressões dos críticos indicam (ARROYO, 1968). Neste estudo, busca-se compreender os discursos em disputa em torno da Bibliotheca Infantil no contexto de sua invenção, cujos vestígios indicam considerável longevidade sob a direção da Editora Quaresma \& C. (1 894 - 1960). Com esta finalidade, de um lado, mapeiam-se e examinam-se anúncios sobre a biblioteca veiculados no periódico $\bigcirc$ Paiz desde as primeiras ocorrências possíveis de se localizar. De outro, procura-se assinalar a crítica sobre os livros que compunham a biblioteca, com especial atenção em relação à arena discursiva (BAKHTIN; VOLOSHINOV, 1994) entre os agentes envolvidos e o lugar social ocupado, à época, por seu destinatário. 
Ademais, observa-se a peculiaridade da pesquisa história que privilegia a seleção, o tratamento e a análise de fontes documentais como os jornais diários. Necessário ter em conta a potencialidade desse tipo de fonte a par dos problemas suscitados, quando do desenvolvimento da investigação. Por meio dos jornais, pode-se, por exemplo, problematizar os discursos dos agentes sociais inseridos no seu tempo histórico, elementos que poderão expor, por meio de instrumental analítico adequado, indícios do projeto editorial examinado, do contexto político e cultural em que estão inseridos. Neste sentido, Vieira acrescenta:

Desmontado o mito da imparcialidade, deparamos com as razões e os procedimentos dos agentes sociais na defesa de projetos, sejam eles políticos, econômicos ou culturais. Nessa direção analítica, o jornal pode ser representado pela metáfora do espelho que reflete a realidade, desde que entendamos, assim como a física explica, que refletir envolve distorção e refração, nesse enfoque, cabe ao intérprete estudar o funcionamento desse sistema de espethamento que discursivamente confere sentidos às coisas, às ações, às palavras ditas ou não ditas (VIEIRA, 2007, p. 16).

Sobre as possibilidades de análise dos discursos em $\bigcirc$ Paiz, adota-se, sobretudo, a perspectiva bakhtiniana. A concepção de linguagem com base nos estudos do Círculo de Bakhtin permite investigações em diferentes áreas do conhecimento, tais como na linguística, na literatura, na psicologia, na antropologia, na história. No âmbito dos estudos discursivos, aqueles que ultrapassam uma abordagem linguística reduzida, verificam-se significativas abordagens alinhadas às colaborações dos estudos bakhtinianos. Em Problemas da Poética de Dostoiévski (1997), por exemplo, Bakhtin advoga que seu objeto de estudo é o "discurso". Nesse sentido, assume que o interesse de sua teoria da linguagem reside em análises efetuadas, baseadas nas relações dialógicas, preservando, nesses termos, a heterogeneidade, a diferença, a alteridade na percepção das cadeias discursivas. Em semelhante perspectiva, as análises realizadas no âmbito deste estudo procuram acentuar tal abordagem, considerando os discursos veiculados no periódico $\bigcirc$ Paiz no seu tempo, em relações amplas, de sentidos dialógicos, como adverte Bakhtin (1997; 1998).

Na primeira parte do artigo, procura-se contextualizar o jornal $\bigcirc$ Paiz em seu tempo. Por um lado, problematizam-se a linha editorial do periódico, os aspectos relacionados à sua produção, à difusão e à capacidade de formar 
a opinião pública. Em seguida, situa-se o investimento da Livraria do Povo na conformação de uma biblioteca destinada às crianças. Ademais, observam-se as estratégias de legitimação do projeto editorial visando à infância daquela época. Por último, analisam-se notas críticas sobre a biblioteca formulada por intelectuais interessados na produção de livros literários para as crianças, levando em consideração as estratégias discursivas por eles encenadas.

\section{O Paiz: um jornal "independente, político, literário e noticioso"}

$\bigcirc$ Paiz, jornal carioca, foi fundado em $1^{\circ}$ de outubro de 1884 por João José Reis Júnior - Conde São Salvador de Matosinhos. Intitulando-se um jornal "independente, político, literário e noticioso", O Paiz enfatizava sua autonomia em relação a grupos específicos, ideário que, na visão dos articulistas, permitiria sua imparcialidade. Definia-se, ainda, como jornal republicano, destacando-se, nos últimos anos da Monarquia, nas campanhas abolicionistas. No entanto, ao se referir a temas polêmicos como o meretrício, em nome dos bons costumes de uma capital federal que se desejava civilizada, era bastante conservador (ARAÚJO, 1993).

224 Em junho de 1906, por exemplo, o jornal publica o que chama de "inquérito do Paiz". Trata-se do "caso Virgolino de Alencar", policial que teria sido demitido injustamente após prender uma meretriz e ser acusado de invadir uma casa de família. Segundo a publicação, o "coração da cidade", que estava sob a atenção da $5^{a}$ circunscrição policial, era lugar de cortejos de "escândalos, desordens e crimes"; formado de

[...] ruas virtualmente vedadas ao trânsito dos cidadãos pacíficos. O mulheril ignóbil não só se exibia em trajes sumários pelas janelas e portas das rótulas, como infestava os cafés e derramava-se pelas ruas em badernas, atentando contra a moral e dando ensejo à prática de crimes. Não era demais dizer que nessa zona da cidade não havia policiamento: eram os mais deletérios elementos sociais que ali dominavam e agiam em plena liberdade. [...]. Foi nessa situação que o Sr. Chefe de polícia teve a feliz inspiração de confiar essa delegacia ao Sr. Dr. Virgolino de Alencar. Era o Dr. Virgolino um funcionário temido e respeitado 1 O CASO VIRGOLINO DE ALENCAR, 1906, p. 2). 
jornal propõe-se, então, a investigar o caso. Apresenta histórico dos donos da casa e de seus inquilinos, buscando justificar a ação da polícia. Conclui que a demissão foi injustificável, pois, na casa invadida, estava uma famosa meretriz. Além disso, a "donzela", que, na ocasião, foi presa, filha da mulher que alugava a casa, teria defendido a meretriz e proferido palavras que só poderia ter aprendido "no meio em que vivia". Observa-se, pois, o alinhamento da linha editorial de $\bigcirc$ Paiz com o pensamento conservador.

Segundo Leal (s/a., p. 1), com a proclamação da República, o jornal "[... ] atingiu sua fase de maior influência na vida política brasileira, tornando-se um dos periódicos mais vendidos da capital federal". Nesse período, também o jornal foi vendido para Francisco de Paula Mayrink, empresário e político.

periódico teve como primeiro redator-chefe Rui Barbosa, que ficou pouco tempo no cargo. Quintino Bocaiúva assumiu a redação do jornal e o dirigiu até 1901. Nomes como Joaquim Serra, Arthur Azevedo, Sebastião de Pinho, Zeferino Cândido, Vitor Godinho, Urbano Duarte, Corina Coaracy, França Júnior e Pinheiro Chagas além de Euclides da Cunha e Carlos de Laet destacaram-se como colaboradores do jornal, principalmente nos primeiros anos de circulação do periódico (MOLINA, 2011 ; CASTILH, 2013).

Nesse período, um exemplar do jornal custava $40 \$$ e a assinatura anual 20\$000. Em meados de 1895, o valor de um jornal avulso já era de 100\$; iá sobre as assinaturas anuais, figuravam, na capa do jornal, em meados de 1895, os valores de $24 \$ 000$ para capital, $28 \$ 000$ para outros Estados e $45 \$ 000$ para estrangeiros. Segundo Barbosa (2010), 100\$ era um preço acessível - com o mesmo valor comprava-se uma passagem de bonde ou o bilhete de travessia de barca (Rio-Niterói). Visando à melhor compreensão da dinâmica de arrecadação do jornal, importa salientar que $\bigcirc$ Paiz (1900-1908) cobrava 150\$ por linha, para que pequenos anúncios fossem publicados.

Em termos de difusão, em dezembro de 1884, o jornal tinha uma tiragem de 19.000 exemplares (CASTILHO, 2013). Entre os anos de 1900 e 1908, a tiragem manteve-se em torno de 15.000 exemplares, havendo relatos, segundo Barbosa (2010), de edições com tiragens entre 28.900 a 30.000 exemplares. Quanto aos aspectos editoriais, no período anteriormente indicado, $\bigcirc$ Paiz publicava edições entre 6 e 12 páginas, com ilustrações e fotografias, além de textos literários como folhetins e crônicas. Os exemplares 
eram produzidos em linotipo e a impressão feita em impressoras rotativas Marinoni ou Walter Scott. Apesar da segunda máquina ser considerada uma moderna impressora, o jornal não publicava edições a cores.

Figura 1

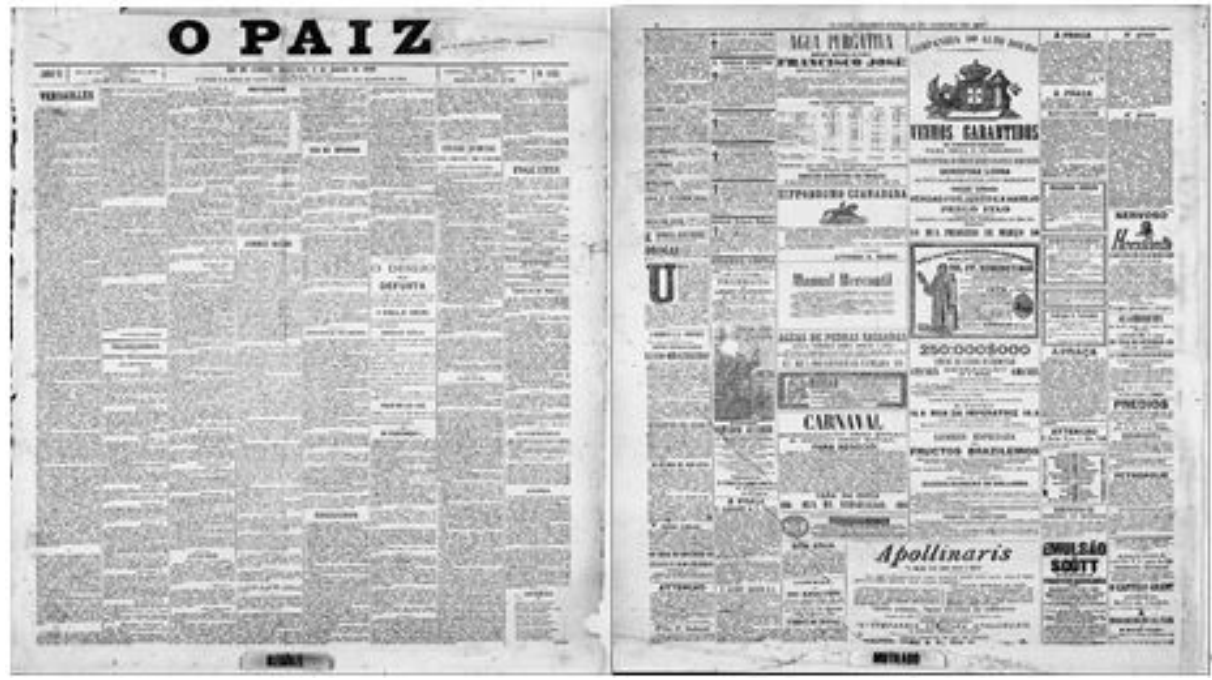

Fonte: $\bigcirc$ Paiz (1890)

periódico também possuía espaços de diálogo com o leitor como "O Paiz nos Subúrbios" e recebia reclamações e sugestões, chegando a publicar cartas que desmentiam notícias do próprio periódico e de outros jornais. Ainda em referência a esse diálogo com o leitor, $\bigcirc$ Paiz realizava concursos diversos e criava espaços de diálogo com grupos específicos, através de enquetes destinadas às mulheres, por exemplo. O jornal, que, em 1906, já publicava textos enviados por crianças e jovens, cria, em 1907, uma seção denominada $\bigcirc$ Paiz das Crianças, por meio da qual veiculava jogos de entretenimento e promovia concursos. No entanto, o jornal possuía maior penetração entre políticos e literatos, "[...] pulverizando uma pequena preferência entre os grupos dominantes"; o que não impediu de, no final da primeira década de 1900, aparecer em "terceiro lugar na preferência do público" (BARBOSA, 2010 , p. $222-2231$.

A partir desse quadro, é possível verificar a importância do jornal $\bigcirc$ Paiz no contexto de sua produção e circulação, tendo em vista o potencial 
de alcançar diferentes camadas sociais e de agir como veículo formador da opinião pública.

\section{Bibliotheca Infantil da Livraria do Povo}

Em razão desse potencial de alcançar diferentes camadas sociais e de destacado meio de divulgação, não é de se estranhar que, nas últimas páginas de $\bigcirc$ Paiz, fosse possível encontrar todo tipo de material publicitário: coletes para senhoras à rua Sete de Setembro, elixir de pepsina composto para amenizar desconfortos do estômago à rua da Assembleia, óleo de mamona quinado para fazer crescer o cabelo na Farmácia Raspail, à rua da Assembleia.

No entanto, em meio às propagandas, chamam a atenção os anúncios que se referem à Quaresma \& C - Livreiros editores ou Livraria do Povo. Tratava-se de um negócio relativo a livros "baratíssimos", como se podia ler nos anúncios. $O$ negócio era conduzido pelo livreiro editor Pedro da Silva Quaresma que lançava uma série de títulos interessantes destinados a esse segmento social: o povo'.

\section{Figura 2}

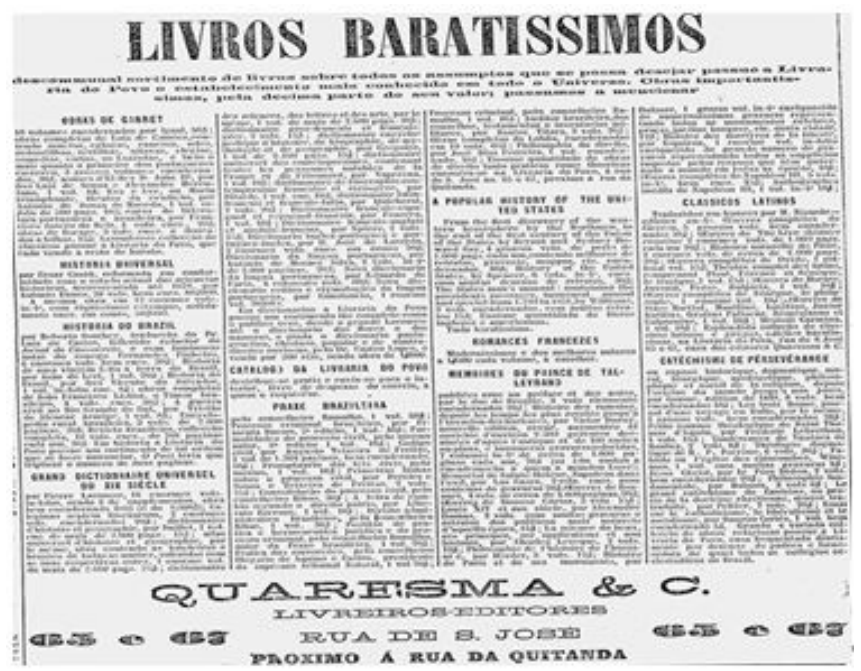

Fonte: O Paiz (1896)

Além dessas informações, os anúncios observados, no período de 1894 a 1900², traziam o endereço da Rua de S. José, 65 e 67 e os tipos de 
publicação que visavam ao leitor popular. Entre os títulos examinados, destacam-se: Arte de fazer sinais com o leque e a bengala; O Dicionário de flores, folhas e frutas ou $O$ manual dos namorados; Manual de Medicina e Cirurgia Veterinária; O padeiro moderno; A mulata; Livro do Criador, A História e a Legenda, Lições de História Geral, Lira Popular; Psicologia das Paixões e $O$ Grande Livro de S. Cypriano; Livro do industrial agrícola ou tratado completo de todas as indústrias ao alcance do lavrador; Orador do Povo. Infere-se, da leitura dos títulos que, segundo o ideário dos editores, o povo devia se interessar por um tipo de leitura de natureza bastante pragmática, isto é, havia certa inclinação para a publicação de manuais de como se comportar em público e mesmo no que dizer em momentos solenes, como batizados, casamentos e enterros.

A Quaresma \& C. - Livreiros Editores ou Livraria do Povo não visava, apenas, ao leitor urbano, visto que os títulos Livro do industrial agrícola ou tratado completo de todas as indústrias ao alcance do lavrador, Livro do Lavrador ou o Tratado completo de agricultura e o Livro do Criador ou o Tratado completo teórico e prático da Zootecnia repetiam-se em vários anúncios. Em alguns casos, anunciavam-se os três volumes em uma única publicação, tendo em 228 vista que os três livros eram de autoria de Manoel Dutra e os leitores aos quais se destinavam eram, provavelmente, os mesmos ${ }^{3}$.

A par dos títulos acima observados, em junho de 1894, a Quaresma \& C - Livreiros editores ou Livraria do Povo esmerava-se no anúncio de um título de livro visando a outro segmento social: a criança. Tratava-se de um título avulso: Contos da Carochinha. No primeiro anúncio localizado, constavam o título e o índice dos contos. Além disso, a estratégia discursiva por parte dos editores buscava seduzir a criança e o adulto, já que se tratava de um livro para a criança que "até o adulto teria prazer na leitura".

Acaba de sair do prelo e acha-se à venda em casa dos editores Quaresma \& C.

Livro para crianças

Contendo uma escolhida coleção de quarenta contos populares, morais e proveitosos de vários países. Um belo volume, nitidamente impresso em ótimo papel [...] 2\$000 ICONTOS DA CAROCHINHA, 1894, p. 7, grifo nosso). 
Concomitante à apresentação do novo título, os editores acentuavam o projeto editorial o qual qualificavam como "único". Em acréscimo, na visão dos editores, convinha indicar o empreendimento que regulava o investimento voltado a formar as crianças brasileiras com habilidade para a leitura. Logo, sublinhavam: consistiam em contos divertidos e ao mesmo tempo proveitosos, o que garantiria leitura edificante pelo viés do bem e da virtude, como se pode ler na continuidade do anúncio:

Os Contos da Carochinha, que ora apresentamos ao público, são estas histórias que todos ouvimos em pequeninos e que sabem todas as crianças de todos os países; é uma escolhida coleção de quarenta magníficos contos populares, que todas as mães de família devem dar a seus filhos para terem, a fim de guiá-los no caminho do bem e da virtude, alegrando-os e divertindo-os ao mesmo tempo (CONTOS DA CAROCHINHA, 1894, p. 7, grifo do autor).

Não se pode deixar de assinalar no anúncio a representação de infância como etapa da vida a ser desfrutada no futuro e a noção de criança brasileira desvinculada de sua origem social, etnia e gênero. Tratava-se, pois, de noções universais, que tornavam invisíveis as crianças reais para as quais os discursos nos anúncios se dirigiam.

A preocupação em criar representações sobre a infância estabelece, no século XVII, um novo sentimento, o qual é legitimado pela fala de moralistas e educadores como indica o já clássico estudo de Ariès ${ }^{4}$ (1986). Esse novo sentimento de infância teria inspirado a educação até o século XX, caracterizando-se pela percepção das particularidades infantis pelas óticas da psicologia e da moralização. Enquanto o primeiro sentimento de infância, descrito pelo historiador, surgira no seio familiar, o segundo estava ligado a um discurso exterior à família e intencionava racionalizar os costumes através da disciplina. Se, por um lado, a escolarização seria responsável por separar a criança dos adultos, criando o modelo de "criança bem educada", outros dispositivos culturais, como o livro, podem ser compreendidos como catalizadores dessas representações de infância, visto que ajudam a delimitar o papel social da criança.

Nessa perspectiva analítica, pode-se entender que a mudança de paradigma sobre a infância e suas representações, que o autor compreendeu como o surgimento do "sentimento de infância", ligado ao sentimento de 
família, não foi um produto espontâneo e neutro das relações no âmbito dos grupos estudados. Associava-se, por assim dizer, aos discursos e embates ideológicos da época.

No que diz respeito à Bibliotheca Infantil, importa examinar o sentimento de infância presente nos anúncios de livros para crianças da Livraria do Povo considerando-se as tensões e embates discursivos entre os diferentes grupos que buscavam deter a palavra de autoridade sobre as crianças e seus modos de existência.

Note-se a respeito dos discursos veiculados nos anúncios, que, em seguida à apresentação das histórias, "as mães de família" poderiam conferir os títulos virtuosos que prometiam assegurar o sugerido caminho "do bem". Indicava-se, de tal modo, cada um dos pequenos contos no sumário:

Os três cães; A bela e a fera; A gata borralheira; João bobo; $\bigcirc$ pequeno polegar; $\bigcirc$ patetinha; Branca como a neve; João e Maria; Jacques e os seus companheiros; Os dois avarentos; Cocota ou a menina desobediente; $O$ perigo da fortuna; Os três presentes da fada; A perseverança; A justiça de Carlos Magno; A guarnição da fortaleza; A briga difícil; O tocador de violino; Os onze irmãos da princesa; Os reis dos metais; O rabino piedoso; $\mathrm{A}$ igreja de Falster; A lenda da montanha; $O$ frade e o passarinho; $\bigcirc$ ratinho reconhecido; Os seis companheiros; $O$ anachoreta; $O$ vaso de lágrimas; Os meninos na mata; O pitassilgo; A fina Alice; Os pêssegos; Jacques e o pé de feijão; Os dois caminhos; $O$ castelo de Kinasi; O irmão e a irmã; A catedral do rei; Os infortúnios do alfaiate João; As três galinhas; $O$ urso e a carriça (CONTOS DA CAROCHINHA, 1894, p. 7).

A relação dos quarenta títulos, como anunciados pelo editor, trazia contos clássicos, como A Bela e a Fera, A Gata Borralheira ou $\bigcirc$ Pequeno Polegar, e outros que, em considerável medida, focalizam temas edificantes como a avareza, a desobediência, a perseverança e a justiça.

No curto espaço de dois anos, entretanto, registram-se, no mesmo periódico, reedições de Contos da Carochinha, notas críticas sobre o empreendimento e o lançamento de outros títulos: Histórias do Arco da Velha, Histórias da Avozinha5, Os Meus Brinquedos, Histórias da Baratinhab.

De tal modo, em novembro de 1896, já não se registram apenas anúncios contendo títulos avulsos. A Quaresma \& C. - Editores e Livreiros 
anuncia, naquele momento, uma completa biblioteca voltada às crianças brasileiras: Bibliotheca Infantil, dedicada especialmente às crianças.

Com a finalidade de dirigir a biblioteca, Pedro da Silva Quaresma convidou o jornalista Alberto Figueiredo Pimentel (1869-1914)7, como se pode ler no anúncio: "Figueiredo Pimentel um dos mais apreciados literatos brasileiros, hoje conhecidíssimo e cada vez mais aplaudido". Pimentel foi, sobretudo, jornalista e cronista. Em 1907, lançou na Gazeta de Notícia a seção denominada $\bigcirc$ Binóculo, com o subtítulo de $\bigcirc$ Rio Civiliza-se que, segundo a crítica, "revolucionou a sociedade carioca".

\section{Figura 3}

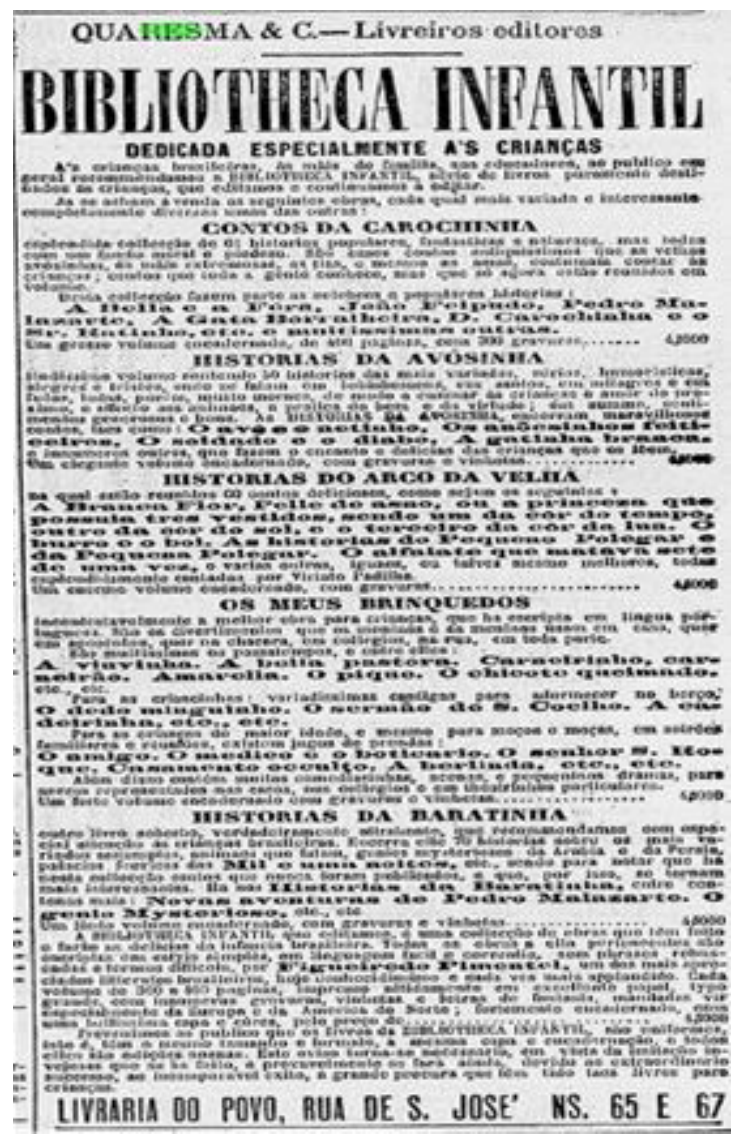

Fonte: O Paiz (1896) 
projeto contou também com a participação do ilustrador e caricaturista Julião Machado. $O$ artista gráfico distinguia a qualidade dos livros da Bibliotheca Infantil por ser considerado caricaturista destacado na imprensa da época, haja vista haver colaborado, inicialmente, com a Gazeta de Notícias, mais tarde, com A Cigarra (que fundou em 1895 com Olavo Bilac), A Bruxa (da qual foi um dos fundadores com João Lage e Olavo Bilac, em 1896), Jornal do Brasil, O Paiz, Jornal do Comércio, A Noite e D. Quixote. ${ }^{8}$

\section{A Bibliotheca Infantil no jornal O Paiz}

No periódico $\bigcirc$ Paiz, é possível verificar diferentes opiniões sobre o investimento da Quarema \& C. - Livreiros Editores em publicar livros destinados ao público infantil. Trata-se de um espaço composto por diferentes vozes, o que faculta a análise sobre a recepção dos livros, haja vista os limites do periódico estudado.

Conforme assinala a historiografia, a nação brasileira é configurada pela imprensa, isto é, os impressos que circularam no país ao longo de duzen232 tos anos testemunham e registram nossa história (DE LUCA; MARTINS, 2015). Nesses termos, o jornal é compreendido neste estudo como documento, o qual, a partir de um manuseio crítico, permite a construção do conhecimento histórico. Cabe assim ao historiador o manuseio das fontes disponíveis e a criação de instrumentos, visando constituir novos dados, como destacado por Nunes e Carvalho:

[... a história começa com o gesto de separação, reunião e transformação em 'documentos', de certos objetos que ganham nova distribuição num certo espaço. $\bigcirc$ trabalho do pesquisador começa quando a partir desse campo já produzido, opera novos recortes, alocamentos e redistribuição dos documentos a partir de ações que visam estabelecer 'suas fontes' e criar a configuração de um espaço específico de investigação, a partir de uma redefinição epistemológica que inclui o trabalho com os conceitos e o tratamento e a interpretação documental (NUNES; CARVALHO, 1993, p. 33).

Conforme a perspectiva teórica sublinhada, foram criados dois instrumentos de pesquisa com a finalidade de se tratar os dados levantados na 
Hemeroteca Digital da Biblioteca Nacional. Por meio da palavra-chave "quaresma", buscaram-se, de início, publicações que pudessem oferecer vestígios sobre a editora Quaresma \& C. e sobre seu investimento em livros para o povo, de maneira geral, no jornal $\bigcirc$ Paiz. Os dados coletados por ano foram alocados em um quadro a partir das entradas: data, edição, página e resumo. Objetivava-se, assim, organizar elementos para a compreensão geral das publicações listadas e uma referência completa, a qual permitisse o retorno ao jornal, quando necessário.

Posteriormente, uma ficha foi elaborada para que apenas os dados referentes à Bibliotheca Infantil fossem detalhados, com base em um resumo expandido e de um campo com reflexões teóricas, além dos dados relativos à edição. Portanto, a partir do investimento no levantamento, organização e sistematização dos dados do periódico estudado, foi possível selecionar notas críticas, artigos e anúncios que permitem a compreensão acurada relativa à conformação da biblioteca estudada e dos discursos que a ela se referem.

Em 1894, por exemplo, alguns dias após o primeiro anúncio localizado sobre Contos da Carochinha, o jornal anunciava uma nota crítica sobre o volume. Segundo a nota, o livro que passava a figurar na "Biblioteca da Livraria do Povo" trazia da língua germânica os contos escritos pelos irmãos Grimm, dos quais não seria possível ocupar-se caso não fossem traduzidos. No entanto, tecem-se duas importantes críticas ao livro, as quais dizem respeito ao conteúdo que levaria as inteligências que desabrochavam a "noções falsas e perniciosas" e à moralidade que era "detestável" nos contos. Em tom irônico, a primeira nota indica que Figueiredo Pimentel teria prefaciado o livro, observando apenas o espírito literário. Contos da Carochinha, segundo aquela análise, não seriam apropriados para crianças. Ou seja, a crítica feita ao livro evidencia o caráter pedagógico e moralizante que circunscrevia os livros editados à época, como se observa no trecho:

Desagradando embora ao Sr. Figueiredo Pimentel, o meigo prefaciador dos Contos da Carochinha, diremos que a moderna arte de educar absolutamente não admite mais semelhantes recursos e repele, mesmo, tudo quanto possa levar às inteligências que desabrocham noções falsas ou perniciosas. Ora, a versão dos Contos da Carochinha, que temos presente, é tudo que pode haver de menos recomendável para o espírito de crianças que se pretende educar, pois thes faz crer que o burro fala ou falou um dia, que o 
galo aperta a mão da gente agradecendo serviços, e vai assim dando ideias de coisas absolutamente inverossímeis. [...] Estamos convencidos de que o Sr. Figueiredo Pimentel prefaciou o livro com espírito somente literário, e por isso não o censuramos: os contos são mais ou menos bem contados e aqui ou ali arranham a gramática, mas que o livro seja apropriado às crianças, a isso é que formalmente nos opomos ([SEM TíTULO], 1894, p. 2, grifo do autor).

No mesmo ano, o jornal veiculou, na segunda página, uma pequena nota tratando da segunda edição do livro. Destacam-se na publicação os aspectos materiais da obra: capricho na impressão do volume, capa primorosa - gravada artisticamente e impressa a cores, além do aumento considerável de gravuras e vinhetas. $\bigcirc$ jornal, que agora apresenta o volume como um "popular livro" que se esgotou rapidamente, aposta em novo sucesso da editora. Lembra, ainda, que embora o livro fosse destinado aos pequenos leitores, os "velhos" tinham prazer em ler "aquelas belas narrações" ([SEM TíTULO]), 1895, p. 2).

Chama também a atenção a nota assinada por Garcia Redondo9

234 (1895, p. 2). Segundo o articulista, o conto denominado o Boi e o Burro seria de sua autoria, contrariando a afirmação de que os contos do livro Histórias do Arco da Velha eram todos traduzidos ou recolhidos da tradição oral. Garcia argumenta que extraiu a história do livro Mil e uma Noites, dando a ele sua interpretação artística. Solicita em tom veemente que o conto seja retirado das edições posteriores ou se publique com a sua assinatura. Nota-se, portanto, que a invenção da Bibliotheca Infantil ocorria em meio a caloroso debate entre aqueles que pretendiam o domínio do campo editorial relativo aos livros destinados às crianças no período.

No entanto, em 1896, em referência ao conjunto de livros para crianças como Bibliotheca Infantil, lê-se na segunda página de $\bigcirc$ Paiz a seguinte nota:

As crianças que tanto apreciam a excelente Bibliotheca Infantil, editada pelos operosos livreiros Quaresma \& C., encontrarão hoje o $5^{\circ}$ volume dessa série, intitulada Histórias da Baratinha, que hoje mesmo será posto à venda. Como os antecedentes, é um livro de contos populares, morais e proveitosos de vários países, porém maior, pois contém 70 histórias e, bem impresso e com gravuras, 
até do notável artista Julião Machado. Já se sabe que hoje à rua de S. José será invadida por uma romaria de crianças, como sucede todas as vezes que os srs. Quaresma \& C. anunciam uma nova obra para a Infância ([NOTA], 1896, p. 2).

Dois dias depois, na primeira página, O Paiz noticia ser "inacreditável o sucesso" que fazia "a série de livros que editam os srs. Quaresma \& C.". Segundo a retórica do jornal, o novo volume - Histórias da Baratinha - que havia sido colocado à venda dois dias antes, havia vendido mil exemplares até duas horas da tarde. Esse era o número de exemplares que havia ficado encadernado para venda e que rapidamente se havia esgotado, deixando "[...] mais de trezentas crianças, que se dirigiam à Livraria do Povo" sem satisfazer a "justa curiosidade, adquirindo um exemplar". No entanto, ao final da pequena notícia, lia-se a informação de que, naquele dia, haveria nova remessa e os jovens leitores poderiam obter o livro ([SEM TíTULO], 1896, p. 1).

Figura 4

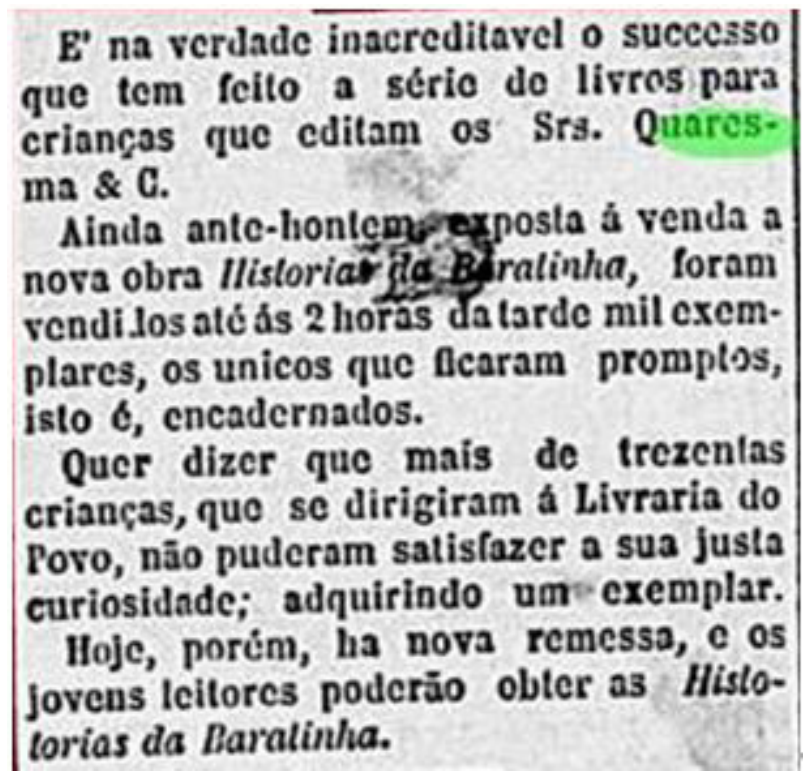

Fonte: O Paiz (1896).

Verifica-se, portanto, nas diferentes publicações aqui elencadas, como o jornal torna-se um espaço de tensões e disputas discursivas. Enquanto os 
editores Quaresma lançam mão de estratégias discursivas e editoriais para chamar a atenção dos leitores, diferentes atores sociais, embora, por vezes, anônimos, colocam-se na discussão sobre a qualidade dos livros para crianças publicados pela editora.

Observe-se, por exemplo, uma publicação de 1899 em que Julia Lopes Almeida ${ }^{10}$, usando pseudônimo de Ecila Worms, critica a obra Contos da Carochinha de Figueiredo Pimentel. A escritora, que também escreve para crianças, classifica o livro como um volume "de perversão". Além disso, ressalta que os contos continham erros ortográficos, ressaltando que "dá-lo a uma criança seria um crime". A crítica contundente coloca novamente em jogo o caráter pedagógico do livro para crianças e seu objetivo de doutrinar a "alma" infantil, como se pode notar do fragmento em destaque:

Tenho um rapazinho que frequentemente me pede livros; cai na asneira de lhe comprar os Contos da Carochinha, porque dessas histórias guarde algumas de cor [...] Antes de the entregar o livro, folheei-o, e... Jesus! Que horror! Que frases bárbaras, que linguagem mastigada; erros, erros, erros e mais erros criçavam todo o livro, tirando-the a graça natural da fantasia, tornando um livro de deleite em um livro de perversão. Fechei zangada o mev exemplar. Dá-lo a uma criança seria um crime. E, desde então, fico tonta sempre que tenha de escolher um livro em português para qualquer criança, porque em todos que por aí andam, como nestas últimas edições de Garnier, vejo o mesmo relaxamento, a mesma pressa, a mesma improbidade literária. Eu já não falo dos livros escolares, destinados propositadamente ao aperfeiçoamento do indivíduo; aludo ao simples livro de passatempo. Onde o encontraremos, como o desejamos? Aqui? Que nos importam as crianças, a cultua da sua inteligência, ou o aperfeiçoamento dos seus sentimentos? Que se embasbaquem nesses períodos sem gramática, sem artes, sem simplicidade, com que os editores exploram a curiosidade dos seus espíritos em botão. Temos mais que fazer, outros cuidados... (A MODA, 1899, p. 11.

Poucos dias depois, Figueiredo Pimentel assina longo artigo em $\bigcirc$ Paiz, sob o título "Contos da carochinha: defesa contra uma agressão". ○ autor replica, em tom veemente, que Julia Lopes de Almeida "pretendia talvez monopolizar a literatura infantil", fato que não conseguiu, pois, se os livros da autora não fossem adotados pela instrução pública, estariam encalhados nas livrarias, sem sucesso. Pimentel, ainda em resposta, relata que os Contos da 
Carochinha foram publicados pela primeira vez no ano de 1894, como um folheto de 200 páginas, possuindo apenas 40 histórias para crianças. No ano de 1899, cinco anos após a primeira edição, o volume já possuía 400 páginas e encontrava-se na $12^{a}$ edição. $\bigcirc$ jornalista ressalta que todos os títulos da Bibliotheca Infantil, por ele compilados, foram publicados pela editora com edições de 5.000 e 10.000 exemplares, os quais circulavam por livrarias de todo o Brasil, inclusive no interior.

Pimentel apresenta, ainda, extensa defesa do seu trabalho, listando suas obras não infantis, sua colaboração em jornais. Trata, também, da consolidação de seu nome no cenário literário, considerando-se "conhecidíssimo, popular, célebre, notável". Segundo o escritor, sua carreira teria sido construída com sacrifício e entrega, à custa de sua saúde. Assim, Julia Lopes de Almeida, "com uma simples penada" tentava derrubá-lo do pedestal "por inveja", por serem "ambos oficiais do mesmo ofício". Finaliza sua "defesa" atacando, de maneira direta, Julia Lopes de Almeida e sua produção:

S. Ex. pretendia talvez monopolizar a literatura infantil. Escreveu os Contos Infantis, naturalmente o primeiro da série. [...]. Se os Contos Infantis não fossem, por empenho, por proteção, adotados efetivamente pela instrução pública, os exemplares dormiriam nas estantes e depósitos do editor, e mais tarde seriam vendidos a peso para embrulhar palitos, manteiga e mais comestíveis. E, para prova, escreva S. Ex. outro livro, não se empenha pela sua adoção, deixe correr o marfim e verá o resultado. [...]. V. Ex. está no seu direito de não gostar dos Contos da Carochinha. Pagamo-nos na mesma moeda, porque, excetuando três ou quatro (não tenho um exemplar a mão), eu também acho que os Contos Infantis estão abaixo da crítica e nada valem, nada absolutamente. Há neles muito termo empatado, muita frase rebuscada, com pretensão de estilo [...]. As crianças brasileiras não entendem termos que ali existem, e que, quando muito, só podem ser compreendidos pelos pequeninos portugueses. [...] Assim, minha senhora, pode V. Ex. chamar-me de burro, brinco, besta, estúpido... o que quiser. Quantos aos Contos da Carochinha, S. Ex. não tem autoridade para mata-lo. Escreva o que quiser, pois não poderá impedir o sucesso dessa obra, a que maior êxito tem causado no Brasil, a que maior número de exemplares tem tirado em tão curto espaço de tempo ICONTOS DA CAROCHINHA: DEFESA CONTRA UMA AGRESSÃO, 1899, p. 3, grifo do autor). 
Ainda como elemento da assinalada disputa, os editores Quaresma \& C. publicam, no dia vinte e nove de janeiro do mesmo ano, um extenso anúncio sobre a $12^{a}$ edição dos Contos da Carochinha. $\bigcirc$ anúncio demarca, uma vez mais, que os contos selecionados são "populares, morais e proveitosos". E adverte:

Crianças brasileiras! Pais ou mães de famílias! Educadores! Tutores!

$\mathrm{O}^{\prime}$ vós que tendes crianças em casa, sob vossa responsabilidades! Comprai e dai-thes a ler o admirável, o soberbo, o extraordinário livro (CONTOS DA CAROCHINHA, 1899, p. 6).

anúncio, que convoca diferentes instâncias associadas à educação das crianças - pais ou mães, educadores, tutores -, destaca crônicas e relatos, que teriam sido publicados em periódicos, os quais tratam da qualidade do livro Contos da Carochinha. Ao final, os editores lançam a advertência: "[...] podem falar os invejosos, pois não destruirão o merecimento dos Contos da Carochinha, o primeiro livro para crianças que se tem escrito no mundo inteiro!!!".

\section{Considerações finais}

Enunciar é argumentar, como sugere Bakhtin, Voloshinov (1994). Nessa direção interpretativa, os discursos escritos veiculados em O Paiz devem ser pensados como estratégias discursivas que visavam ao interlocutor dos artigos escritos pela equipe editorial, Garcia Redondo, Julia Lopes de Almeida, assim como o auditório social mais amplo previsto: os leitores do periódico e, por derivação, as crianças sob sua tutela.

De início, observou-se $\bigcirc$ Paiz como fonte privilegiada de divulgação de uma biblioteca infantil a ser consolidada. Ao se verificarem as amplas tiragens e os preços acessíveis do periódico para distintas camadas da população, notou-se de igual modo a possibilidade de se considerar o periódico como forma de divulgação eficiente.

Por outro lado, examinaram-se as possibilidades de levantamento, tratamento e organização das fontes registradas no periódico na perspectiva da historiografia da educação e fontes, por meio dos instrumentos considerados 
adequados, como as fichas de registro e consulta, e elaborados no âmbito da pesquisa histórica.

Em seguida, focalizaram-se os debates derivados da invenção de uma biblioteca destinada à criança formada, em grande parte, por contos considerados morais e proveitoso e extraídos da tradição oral. Se, de um lado, a equipe editorial esmerava-se na propaganda da biblioteca como a "única" contendo contos virtuosos para a formação da criança; de outro, os potenciais adversários usavam toda sorte de argumento para desqualificar o empreendimento, como foi possível observar nos argumentos tecidos por Garcia Redondo e pela também escritora de livros infantis, Julia Lopes de Almeida.

Por último, evidenciou-se, com base nas fontes examinadas, como o debate sobre os livros de ficção apropriados às crianças no período estudado estava presente na conformação da Bibliotheca Infantil e nos discursos em disputa sobre o empreendimento editorial analisados no âmbito do jornal $\bigcirc$ Paiz. Não se tratava de meros comentários registrados nas páginas do periódico sobre uma coleção de livros infantis "proveitosos e divertidos". A invenção da Bibliotheca Infantil ocorria em meio à acirrada disputa discursiva entre aqueles que pretendiam o domínio do campo editorial relativo aos livros destinados às crianças no último quartel do século XIX.

\section{Notas}

1 Verificar informações adicionais sobre a abrangência da Quaresma \& C - Livreiros editores ou Livraria do Povo em EL FAR, 2004, cuja pesquisa tematiza a literatura popular e pornográfica no Rio de Janeiro (1870-1924).

2 Trata-se de uma das fontes utilizadas para se compreender a conformação da Bibliotheca Infantil da Quaresma \& C. - Livreiros Editores, conforme os objetivos da pesquisa em andamento financiada pela FAPERJ e CNPQ.

3 No dia 14 de abril de 1895, é veiculado em $\bigcirc$ Paiz o anúncio intitulado "Enciclopédia Rural Brasileira" em que o Livro do lavrador, Livro do criador e o Livro do industrial agrícola eram apresentados, em detalhes, ao público (Enciclopédia Rural Brasileira, 1895, p. 6). No entanto, pequenos anúncios, ainda em 1894, já indicavam a tendência de apresentar os livros de maneira conjunta.

4 Desde 1960, ano em que o estudo l'Enfant e la vie familiale sous l'Ancien Régime foi lançado na França, algumas de suas conclusões foram refutadas e revistas por estudiosos interessados na construção social da infância e pelo próprio autor. Uma das principais ressalvas sobre a obra de Ariès refere-se ao uso das fontes, produzidas, em grande medida, no âmbito da nobreza e da burguesia francesa.

5 Cf. O Paiz, 10 ago. de 1896 (Histórias da Avozinha, 1896, p. 4). A esse respeito, verificar, também, o exame realizado por SILVA (2016), que, além de examinar alguns contos sobre a 
sociedade de corte que conformam a obra, mobiliza operação metodológica que dá a ver aspectos materiais da coleção.

6 A primeira ocorrência encontrada em $\bigcirc$ Paiz do livro Os meus Brinquedos refere-se a um anúncio sob o título de "Livros para Crianças", ( 1896, p. 5). O livro também passa a ser anunciado de maneira avulsa. $O$ mesmo ocorre com o livro Histórias da Baratinha, localizado no jornal, que figura no anúncio sobre a Bibliotheca Infantil da Editora Quaresma (Bibliotheca Infantil, 1896, p. 8).

7 Alberto Figueiredo Pimentel - Pseudônimo Fifi. Nasceu em Macaé (RJ), a 11 de outubro de 1869. Faleceu no Rio (GB), a 5 de fevereiro de 1914. (MENEZES, 1969)

8 MACHADO, Julião (J. Félix.M. São Paulo de Luanda, Angola, 1863 -Lisboa, Portugal, 1930). Conferir em Ayala (1973).

9 Manuel Ferreira Garcia Redondo (Rio de Janeiro, 1854 - São Paulo, 1916). Durante sua vida, desempenhou atividades como engenheiro, jornalista, professor, contista e teatrólogo. Foi fundador da cadeira $n^{\circ} 24$ da Academia Brasileira de Letras. Sendo colaborador de diferentes periódicos, utilizava pseudônimos diversos: Um contemporâneo, Um plebeu, Cabrion (Biografias, Academia Brasileira de Letras).

10 Julia Valentina Lopes de Almeida (Rio de Janeiro 1862 - Rio de Janeiro 1934). Exerceu atividades diversas. Destacam-se contos, romances, crônicas e literatura infanto-juvenil. Inicia suas atividades jornalísticas em A Gazeta de Campinas. Em, 1884, começa a colaborar com o jornal $\bigcirc$ Paiz. Com sua irmã, Adelina Lopes Vieira, publica Contos Infantis, em 1887. (Enciclopédia ltaú Cultural, 2017).

\section{Referências}

A MODA. O Paiz, Rio de Janeiro, p. 1, 21 jan. 1899.

ARAÚjO, Rosa Maria Barboza de. A vocação do prazer: a cidade e a família no Rio de Janeiro republicano. Rio de Janeiro: Rocco, 1993.

ARIĖS, Philippe. História social da criança e da família. Tradução Dora Flaksman. 2. ed. Rio de Janeiro: Editora Guanabara, 1986.

ARROYO, Leonardo. Literatura infantil brasileira: ensaio de preliminares para a sua história e suas fontes. São Paulo: Melhoramentos, 1968.

AYALA, Walmir (Coord.). Dicionário brasileiro de artistas plásticos Brasília: Instituto Nacional do Livro/Ministério da Educação e Cultura, 1973.

BARBOSA, Marinalva. História cultural da Imprensa no Brasil - 1800-1900. Rio de Janeiro: Mauad X, 2010. 
BAKHTIN, Mikhail; VOLOSHINOV, Valentin Nikoláievich. Marxismo e filosofia da linguagem (1929). Tradução Michel Lahud e Yara Frateshi Vieira. 7. ed. São Paulo: Hucitec, 1994.

BAKHTIN, MiKhail. Problemas da poética de Dostoiévski (1929). 2. ed. Tradução Paulo Bezerra. Rio de Janeiro: Forense Universitária, 1997.

BAKHTIN, Mikhail. Questões de literatura e de estética: a teoria do romance (1975). Tradução Bernadini et al. 4. ed. São Paulo: Editora da Unesp, 1998

BIBLIOTHECA Infantil. O Paiz, Rio de Janeiro, p. 8, 12 nov. 1896.

CAPA. O Paiz, Rio de Janeiro, p. 1, 2 jan. 1890.

CASTILHO, Marcio de Souza. "O amigo incondicional de todos os governos": a trajetória de João Lage em $\bigcirc$ Paiz nos primeiros anos da República. In: ENCONTRO NACIONAL DE HISTÓRIA DA MÍDIA, 9, 2013. Anais... Ouro Preto: Universidade Federal de Ouro Preto, 2013.

CONTOS da Carochinha. O Paiz, Rio de Janeiro, p. 7, 15 jun. 1894.

CONTOS da Carochinha. O Paiz, Rio de Janeiro, p. 6, 29 jan. 1899.

CONTOS da carochinha: defesa contra uma agressão. O Paiz, p. 3, Rio de Janeiro, 26 jan. 1899.

DE LUCA, Tania Regina e MARTINS, Regina. História da imprensa no Brasil. São Paulo: Contexto, 2015.

ENCIClOPÉDIA Rural Brasileira. O Paiz, Rio de Janeiro, p. 6, 14 abr. 1895.

ITAÚ Cultural. Júlia Lopes de Almeida. In: Enciclopédia Itaú Cultural de Arte e Cultura Brasileiras. São Paulo: Itaú Cultural, 2017. Disponível em: <http://enciclopedia.itaucultural.org.br/pessoa443758/julia-lopes-de-almeida>. Acesso em: 15 mar. 2017.

EL FAR, Alessandra. Páginas de sensação. Literatura popular e pornográfica no Rio de Janeiro (1 870-1924). São Paulo: Companhia das Letras, 2004.

HISTÓRIAS da avozinha. O Paiz, Rio de Janeiro, p. 4, 10 ago. 1896.

LEAL, Carlos Eduardo. O País. In: Centro de Pesquisa e Documentação de História Contemporânea do Brasil (CPDOC). Fundação Getúlio Vargas. Disponível em: <http:// cpdoc.fgr.br/sites/default/files/verbetes/primeira-republica/PA\%C3\%8DS,\%200.pdf>. Acesso em: 22 nov. 2016. 
LIVROS baratíssimos. O Paiz, Rio de Janeiro, p. 8, 27 fev. 1896.

LIVROS para crianças. O Paiz, Rio de Janeiro, p. 5.4 set. 1896.

MENEZES, Raimundo de. Dicionário literário brasileiro ilustrado. São Paulo: Saraiva Livreiro Editores, 1969 (v. 4).

MOLINA, Matías Martínez. Um jornal de aluguel. Observatório da Imprensa, nov. 2011. (edição 679). Disponível em: <http://observatoriodaimprensa.com.br/imprensa-em-questao/um-jornal-de-aluguel/>. Acesso em: 22 nov. 2016.

NUNES, Clarice; CARVALHO, Marta Maria Chagas de. Histografia da educação e fontes. Cadernos Anped, Porto Alegre, n. 5, p. 7-64, set. 1993.

O CASO Virgolino de Alencar. O Paiz, Rio de Janeiro, p. 2, 20 jun. 1906.

REDONDO, GARCIA. Academia Brasileira de Letras. Disponível em: http://www.academia.org.br/academicos/garcia-redondo/biografia. Acesso em: 16 mar. 2017.

REDONDO, Garcia. Sem título. O Paiz, Rio de Janeiro, p. 2, 9 set. 1895.

[SEM TÍTULO]. O Paiz. Rio de Janeiro, p. 2, 18 jun. 1894.

242 [SEM TÍTULO]. O Paiz. Rio de Janeiro, p. 2, 21 ago. 1894.

[SEM TÍTULO]. O Paiz, Rio de Janeiro, p. 2, 9 set. 1895.

[NOTA]. O Paiz, Rio de Janeiro, p. 2, 24 dez. 1896.

[SEM TÍTULO]. O Paiz, Rio de Janeiro, p. 1, 26 dez. 1896.

SILVA, Márcia Cabral da. Histórias da Avósinha (1936): contos clássicos e da tradição oral em meio aos livros para crianças de seu tempo. In: SOUZA, José Antonio de; SLAVEZ, Milka Helena Carrilho; FREITAS, Silvane Aparecida de (Org.) Linguagem, educação e cultura: abordagens, pesquisas e ensino. São Carlos: Pedro \& João Editores, 2016.

VIEIRA, Carlos Eduardo. Jornal diário como fonte e como tema para a pesquisa em História da Educação: um estudo da relação entre imprensa, intelectuais e modernidade nos anos de 1920. In: OLIVEIRA, Marcus Aurélio Taborda (Org.). Cinco estudos em história e historiografia da educação. Belo Horizonte: Autêntica, 2007. 
Profa. Dr ${ }^{a}$. Márcia Cabral da Silva

Universidade do Estado do Rio de Janeiro

Faculdade de Educação

Programa de Pós-Graduação em Educação

Líder do Grupo de Pesquisa Infância, Juventude, Leitura, Escrita e Educação | CNPQ

E-mail | marciacs@ism.com.br

Graduanda Mariane Sousa Pinto Universidade do Estado do Rio de Janeiro

Faculdade de Educação

Curso de Pedagogia

Bolsista de Iniciação Científica | CNPQ Grupo de Pesquisa Infância, Juventude, Leitura, Escrita e Educação | CNPQ E-mail |maris.sousa95@gmail.com

Recebido 29 out. 2017 Aceito 12 dez. 2017 